\title{
O "progresso" em Blumenau/SC: educação, pobreza e desigualdade social no território de uma escola
}

\author{
Sandra Pottmeier ${ }^{1}$, Apoliana Regina Groff $^{2}$ e Melissa Probst ${ }^{3}$
}

1 Doutoranda em Linguística pela Universidade Federal de Santa Catarina, Mestre em Educação pela Fundação Universidade Regional de Blumenau, Especialista em Educação, Pobreza e Desigualdade Social pela Universidade Federal de Santa Catarina e Graduada em Letras pela Fundação Universidade Regional de Blumenau. Professora na rede estadual de ensino de Santa Catarina, Brasil. E-mail: pottmeyer@gmail.com

2 Doutora e Mestre em Psicologia da Universidade Federal de Santa Catarina e formada em Psicologia pela Fundação Universidade Regional de Blumenau. Pesquisadora do Núcleo de Pesquisa em Práticas Sociais: relações éticas, estéticas e processos de criação (NUPRA/PPGP/UFSC), Brasil. E-mail: poligroff@gmail.com

3 Doutora em Educação pela Universidade Tuiuti do Paraná, Mestre em Educação pela Universidade Regional de Blumenau, Graduada em Pedagogia pela Universidade Regional de Blumenau e Graduada em História pelo Centro Universitário Leonardo da Vinci. Brasil. E-mail: mel.probst@gmail.com

RESUMO: Este texto reflete a relação entre educação e pobreza e problematiza o papel da escola frente às desigualdades sociais presentes no seu território. $\mathrm{O}$ território aqui em destaque diz respeito ao Bairro Progresso localizado no município de Blumenau/SC. Trata-se de um estudo de caso no qual os principais recursos metodológicos utilizados foram: Data Social 2.0, Mapa Temático de Vulnerabilidade Social (MAVS), dados do Censo do IBGE (2010) e contribuições de autores/as cujos estudos focam o município em questão. Conhecida nacionalmente por possuir uma economia em franco desenvolvimento, comparada à Alemanha (Blumenau como cidade alemã) situada no chamado "Vale Europeu", também é perpassada pelas mazelas da desigualdade social que assujeita milhares de pessoas à pobreza, indivíduos estes que estão vivendo basicamente em ocupações irregulares e áreas de risco. Neste contexto vivem crianças e adolescentes em idade escolar, em realidades que são, por vezes, negligenciadas tanto pela sociedade quanto pelos docentes, no contexto escolar. Considera-se, entretanto, que os profissionais da educação precisam (re)conhecer a realidade do território escolar, rever suas ações político-pedagógicas visando a não reprodução das desigualdades sociais nas relações educativas, bem como compreender que a pobreza se constitui em uma violação dos direitos humanos.

Palavras-chave: Educação. Pobreza. Desigualdade Social. Direitos Humanos. Blumenau/SC.

The "progress" in Blumenau/SC: education, poverty and social difference in the territory of a school ABSTRACT: This text reflects the relationship between education and poverty and problematizes the role of the school in face of the social inequalities present in its territory. The territory here in focus concerns the Progresso district located in the Blumenau/SC. It is a study of a case study whose main methodological resources were: Social Data 2.0, Thematic Map of Social Vulnerability (MAVS), data from the IBGE Census (2010) and contributions from authors whose studies focus on the municipality in question. It has known nationally for having a rapidly developing economy, compared to Germany (Blumenau as a German city) in the so-called "European Valley", it is also beset by the ills of social inequality that afflicts thousands of people to poverty, individuals who are basically living in Irregular occupations and areas at risk. In this context live children and adolescents of school age, in realities, are sometimes neglected by both society and teachers in the school context. It is considered, however, that education professionals need to (re) know the reality of the school territory, review their political-pedagogical actions aiming at the non-reproduction of social inequalities in educational relations, and understand that poverty constitutes a violation of human rights.

Keywords: Education. Poverty. Social Difference. Human Rights. Blumenau/SC.

\section{INTRODUÇÃO}

No Brasil, a produção acadêmica sobre a relação entre educação e pobreza não é necessariamente expressiva no contexto das ciências sociais e humanas. Um estudo 
que analisou artigos, dissertações e teses, publicadas entre 1999 e 2009, encontrou 69 trabalhos que abordam com centralidade a relação entre situação de pobreza e educação formal (YANNOULAS; ASSIS; FERREIRA, 2012). As autoras destacam certa concentração das pesquisas nos anos de 2007 e 2008 com ênfase na área da educação, mas também da economia e do serviço social. De modo geral, não há uma consolidação da temática em nenhuma instituição de ensino superior, bem como na trajetória acadêmica dos/as autores/as dos trabalhos, o que aponta certa dificuldade na constituição de linhas de pesquisa.

Este contexto leva a pensar inicialmente que, apesar da marcante desigualdade social que faz com que milhões de pessoas se encontrem em situação de extrema pobreza e pobreza no Brasil, sendo muitas destas crianças e adolescentes em idade escolar, não há um agrupamento de estudos e pesquisas significativos que permita (re)conhecer a complexidade da relação entre educação e pobreza. Tem-se como certo que nas últimas décadas ocorreu praticamente a universalização do acesso à educação, sobretudo, à educação básica por meio de políticas educacionais mais democráticas e preocupadas, certamente, com o controle social e com o desenvolvimento econômico do país (BRASIL, 2004; 2008; 2012, 2015). As portas das escolas foram abertas e se condiciona, atualmente, aproximadamente 14 milhões de famílias $^{1}$ em situação de ex-

\footnotetext{
${ }^{1}$ Em junho de 2016 foram registradas 13.805.497 miIhões de famílias beneficiárias do Programa Bolsa Família no país. Fonte: Painel de acompanhamento da conjuntura e de programas sociais, Ministério do Desenvolvimento Social. (Disponível em: <http://aplicacoes. mds.gov.br/sagi/MONIB2/index_all_drop_down.php?p _id $=418 \& p \_g \mid$ obal_ibge $=\& p \_f e r r a m e n t a s=1 \& p \_s e m \_$ legenda=1>. Acesso em: 20 jul. 2016.)
}

trema pobreza e pobreza a terem seus filhos e filhas frequentando essa instituição, como forma de garantir o direito de serem beneficiárias de uma política de transferência de renda, a saber, o Programa Bolsa Família (PBF) (TELES; STEIN, 2013).

Neste bojo, apesar das crianças e dos adolescentes pobres adentrarem os contextos escolares carregando suas vivências, saberes e olhares sobre o mundo, ou seja, modificando de algum modo a paisagem escolar, do ponto de vista político e pedagógico, a escola permaneceu e permanece ainda a mesma. Os currículos que se objetivam nas práticas pedagógicas continuam, em sua grande maioria, desconsiderando as desigualdades socioeconômicas, o território habitado pelas crianças e adolescentes, seus saberes e culturas, as opressões de gênero, de classe e raça/etnia. A escola ainda projeta a imagem de um estudante branco, classe média, sem deficiência, católico $^{2}$, isto é, um suposto estudante "normal". Com isso, a escola (re)produz cotidianamente desigualdades educacionais constituindo processos de inclusão perversos (SAWAIA, 2008).

Para Assis e Yannoulas (2012) há uma preocupação em observar, em alguns estudos, discursos de professores e professoras vinculados a escolas públicas que recebem estudantes em situação de pobreza. Muitos "consideram que a escola deve se preocupar exclusivamente com a aprendizagem e não com questões relacionadas à situação de pobreza ou à desigualdade social" (ASSIS; YANNOULAS, 2012, p. 253). Estes auto-

\footnotetext{
${ }^{2}$ Destacamos que até o advento da república, o Brasil era um país oficialmente católico (previsto em Lei) e que mesmo depois a Igreja Católica continuou exercendo influências significativas na constituição cultural e moral do país.
} 
res, ao analisar as diretrizes e o currículo de um curso de pedagogia e ao realizar entrevistas com futuros profissionais, concluíram que na formação destes docentes a questão da pobreza/desigualdade social não é tratada diretamente. Isso nos faz perguntar: que tipo de acolhimento e respostas a educação brasileira tem dado às crianças e aos adolescentes pobres que adentram a escola? Há o (re)conhecimento da situação de pobreza vivida por estes sujeitos? Suas vivências são consideradas no processo de escolarização? Como os professores têm estabelecido relações educativas com estes sujeitos e suas famílias?

Entendemos que é preciso, de um lado, (re)conhecer e compreender as multidimensões da pobreza "para repensar os currículos e as práticas educacionais; de outro, cultivar nossa sensibilidade para ouvir e incorporar, em nosso exercício profissional, as questões que ecoam das vivências da pobreza" (ARROYO, 2015a, p. 6). Nesta direção, este trabalho objetiva refletir sobre a relação entre educação e pobreza e, mais especificamente, problematizar o papel da escola frente às desigualdades sociais presentes no seu território.

\section{MÉTODO: ESTUDO DE CASO}

Para a realização do presente trabalho foi eleito o estudo de caso como modalidade de investigação, uma vez que se entende que este permite a leitura fenomenológica e qualitativa de um determinado objeto, abarcando ainda os aspectos quantitativos e estatísticos que o compõem. Considerando os objetivos propostos, o estudo de caso pode ser classificado como instrumental (VENTURA, 2007), pois ao analisar o território de uma escola situada em um determi- nado bairro e município busca-se problematizar uma questão mais ampla, isto é, o papel da escola e dos profissionais da educação frente a esse contexto.

Assim, este estudo "visa à investigação de um caso específico, bem delimitado, contextualizado em tempo e lugar para que se possa realizar uma busca circunstanciada de informações" (VENTURA, 2007, p. 384). Nesse âmbito, as informações aqui produzidas estão atravessadas por aspectos históricos, demográficos e geográficos do Bairro Progresso em Blumenau/SC, com foco nas questões que envolvem a desigualdade social e a pobreza.

Os recursos metodológicos utilizados foram duas ferramentas disponibilizadas pelo Ministério do Desenvolvimento Social e Combate à Fome (MDS) através da Secretaria de Avaliação e Gestão da Informação (SAGI): o Data Social 2.0 e o Mapa Temático de Vulnerabilidade Social (MAVS). O MAVS é um "aplicativo que permite a construção de mapas temáticos de indicadores relacionados à condição de vulnerabilidade social em nível intramunicipal para todos os municípios brasileiros" ${ }^{\prime 3}$.

A partir dos recursos selecionados, ao escolher o estado e o município é possível eleger um indicador. No caso do presente estudo, o indicador escolhido foi o "Percentual de domicílios particulares próprios com renda domiciliar per capita de até 70 reais", uma vez que a intenção inicial era verificar a concentração de domicílios no território do município onde pessoas se encontram em situação de extrema pobreza.

O Data Social é uma plataforma online que "disponibiliza dados e indicadores para

3 Disponível em: <http://aplicacoes.mds.gov.br/ sagidata/METRO/metro.php?p_id=4>. Acesso em: 20 jul. 2016. 
elaboração de diagnósticos atualizados e para monitoramento das políticas e programas do Ministério [do Desenvolvimento Social], além de informações de contexto social, demográfico e econômico de municípios, estados, regiões e Brasil" ${ }^{4}$. Dentre o conjunto de dados, indicadores, boletins e do painel de conjuntura e programas sociais disponíveis na plataforma, utilizamos para este estudo, principalmente os seguintes: Diagnóstico Municipal, onde trabalhamos com os dados do Brasil Sem Miséria - município de Blumenau/SC (Relatório gerado em 27 de maio de 2016); com o indicador de Extrema Pobreza segundo o Censo Demográfico de 2010 e; com os indicadores do Painel Síntese do Plano Brasil Sem Miséria, a partir do qual podemos observar a quantidade de famílias que recebiam o benefício do Programa Bolsa Família em Blumenau/SC.

Foram utilizados também dados do Censo Demográfico realizado no ano de 2010 pelo Instituto Brasileiro de Geografia e Estatística (IBGE), bem como informações de moradores que residem no território do entorno da escola; contribuições de autores em que os estudos focam o município em questão e de outros autores que nos ajudam a refletir sobre a relação entre educação e pobreza.

\section{0 “PROGRESSO" EM BLUMENAU}

Blumenau, apesar de se apresentar para o Brasil e internacionalmente como uma cidade "alemã $\tilde{5}^{5}$ socialmente e economica-

\footnotetext{
4 Disponível em: <http://aplicacoes.mds.gov.br/sa girmps/mapas_pobreza_mapa/cifam.php $>$. Acesso em: 20 jul. 2016.

${ }^{5} \mathrm{Em}$ menção à cultura instaurada pelo processo de colonização por imigrantes alemães.
}

mente forte, "esconde" por entre seus vales e morros, uma significativa população em situação de extrema pobreza e pobreza, sendo a "cidade catarinense com o maior número de favelas" (MOSER; IJUIM, 2015, p. 134). Mas o que significa ser pobre e extremamente pobre? Do ponto de vista exclusivamente monetário, o governo brasileiro estabelece a "linha que separa pobreza renda mensal per capta de até $\mathrm{R} \$ 154-\mathrm{e}$ pobreza extrema - renda mensal de até R\$ 77 por pessoa" (REGO; PINZANI, 2015, p. 19).

A afirmação anterior pode gerar certo receio aos que conhecem o município da famosa Oktoberfest, seja pessoalmente ou pelo apresentado pelos meios de comunicação. Contudo, os dados do Censo Demográfico do IBGE de 2010 revelam que Blumenau ocupa o primeiro lugar na lista de cidades catarinenses com domicílios em "aglomerados subnormais", ou seja, moradias "agrupadas em regiões carentes de serviços públicos essenciais, como abastecimento de água, disponibilidade de energia elétrica e saneamento básico" (Jornal de Santa Catarina, 2012).

Segundo dados do Data Social 2.0, a população do município era de 338.876 mil habitantes. Há no município de Blumenau um total de 6,8 mil domicílios localizados em aglomerados subnormais, o que equivale a $6,7 \%$ do total de moradias particulares na cidade. Há 23 mil pessoas que vivem nesta condição, e destas, 1.664 pessoas se encontram em situação de extrema pobreza, com renda per capta de até 77 reais/mês ou aproximadamente 2,5 reais/dia (IBGE, 2010). Já a outra parcela de pessoas que vivem nestes aglomerados se encontra na linha da pobreza. Para complementar estas informações com números de 2016, o 
município possui 10.228 famílias registradas no Cadastro Único do MDS e, deste total há 3.037 pessoas que são beneficiárias do Programa Bolsa Família. Cabe destacar que pela quantidade de famílias cadastradas, o número de pessoas em situação de pobreza pode ser ainda maior se supormos que cada família possui mais de dois integrantes.

Ao fazer uso do aplicativo MAVS, utilizando o indicador de percentual de domicílios em extrema pobreza em Blumenau, foi possível observar que a área na qual se localiza o Bairro Progresso, região sul da cidade, em que está localizado também o Parque Nacional da Serra do Itajaí, há uma concentração de domicílios com pessoas vivendo na extrema pobreza que varia entre $0.69 \%$ e $0.93 \%$ (laranja escuro, à esquerda do mapa). Já a parte vermelha do mapa, revela uma maior concentração, sendo maior ou igual a $0,94 \%$.

Mapa 1 - Município de Blumenau.

Map 1 - Blumenau City.

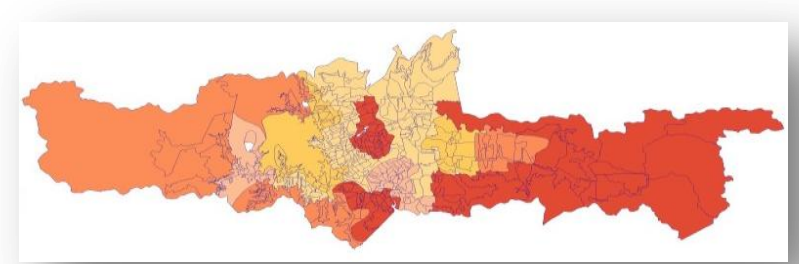

Fonte: MAVS, 2016.

A partir dos dados apresentados pelo MAVS, as impressões que tínhamos, sobre a concentração da pobreza no município de Blumenau coincidem, haja vista as localidades em que estas pessoas estão vivendo. São bairros próximos à região central do município, tal como o Bairro Ribeirão Fresco e o Vorstadt; ao sul no Distrito do Garcia, aonde se localiza o Bairro Progresso e; ao norte, os bairros Itoupavazinha e Itoupava Central, que vêm recebendo nos últimos anos um contingente de pessoas de outras regiões do país, principalmente da região nordeste, em busca de melhores condições de vida por intermédio do trabalho.

Analisando estas informações é possível afirmar que há uma significativa população em situação de pobreza em Blumenau, ou seja, com renda per capita de até $\mathrm{R} \$ 144$ reais/mês ou aproximadamente 5 reais/dia, morando em diferentes regiões da cidade, incluindo o Bairro Progresso. A questão é: esta realidade é de fato (re)conhecida? Enquanto docentes, reconhecemos nas escolas as crianças e adolescentes que vivem nesta situação social? Que realidade adentra os muros da escola? Dispomo-nos a oIhar mais de perto o território ocupado pela escola e, consequentemente, pelos estudantes? O que é sabido sobre o nosso contexto de trabalho?

O artigo de Moser e ljuim (2015) "A prática da invisibilidade social sobre as áreas de concentração de pobreza na imprensa de Blumenau (SC)", e a tese de Samagaia "Globalização e Cidade: Reconfigurações dos Espaços de Pobreza em Blumenau/SC" (2010) apontam para a história de um município perpassado pela concentração de sujeitos pobres nos morros do centro da cidade, bem como os processos de exclusão e segregação que foram invisibilizando a existência destes ao longo dos anos. Uma das primeiras "favelas" em Blumenau, chamada pelos 102 moradores que ali viviam de "Favela Farroupilha", localizava-se próximo à chamada ponte de ferro (Ponte Aldo Pereira de Andrade), ponto turístico localizado em frente à atual Prefeitura Municipal de Blumenau, no centro do município.

Samagaia (2010) ressalta que essas famílias foram removidas do centro do munícipio para os bairros para que as mazelas da 
desigualdade social pudessem ficar escondidas, ou seja, foram retiradas de um lugar que estava em plena ascensão industrial na década de 1940. Assim, bairros conhecidos popularmente como "Beco Araranguá" (atual Rua Araranguá - Distrito Garcia) e "Beco das Cabras" (hoje Rua Pedro Krauss Sênior - Bairro Vorstadt) eram considerados "refúgios" da pobreza que aparecia "com mais evidência na paisagem urbana" e, que começava "a produzir incômodos" para aquela sociedade constituída por imigrantes alemães vindos na comitiva de Dr. Blumenau em 1850 (SAMAGAIA, 2010, p. 106). Infelizmente,

Esses locais até hoje são conhecidos desta forma, ou seja, lugares onde a pobreza é predominante, mas longe do olhar de quem visita a cidade ou mora nas áreas mais privilegiadas. São locais cujos moradores dão continuidade à situação em que se encontravam; isto é, em sua grande maioria convivem com habitações precárias, em terrenos "irregulares" ou áreas de risco, infra-estrutura urbana precária ou inexistente, falta de áreas de lazer e convivência, etc. Estas comunidades, historicamente situadas na parte avessa da cidade, receberam pouca atenção das administrações públicas e tem seus problemas se agravarem nos últimos anos em função das novas ocupações que vão se concretizando, do empobrecimento dos moradores locais, da inserção do tráfico de drogas, e da precarização da vida como um todo (SAMAGAIA, 2010, p. 107108).

Cabe ainda mencionar que a partir da década de 1970, no auge do desenvolvimento da Indústria Têxtil no município, o aumento de pessoas vindas do interior de
Santa Catarina e Paraná era crescente. Muitas delas fizeram suas moradas em locais mais próximos de rios. Devido às grandes enchentes na década de 1980, passaram a residir em localidades mais altas (portanto morros) e, com isso, passaram a sofrer com os deslizamentos de terras. Assim, apesar de Blumenau construir uma imagem de cidade "alemã", deve-se levar em consideração que nela há muitos imigrantes dos estados vizinhos e do interior de Santa Catarina. Há também uma população negra significativa, aproximadamente $10 \%$ dos habitantes do município, segundo dados do IBGE (2010). Há, portanto, todo um contexto geopolítico em torno das pessoas que moram nos "morros", além de uma questão que é histórica, mas também atual, envolvendo as enchentes e os deslizamentos ${ }^{6}$.

Ao discorrer um pouco sobre algumas características e mudanças urbanas no Bairro Progresso e no próprio município de Blumenau, observa-se que há um discurso, da maioria dos blumenauenses, de não reconhecimento da desigualdade social e da pobreza que aparece de forma mais efetiva nos morros da cidade. A própria compreensão de morro versus favela também se torna ponto de discussão, pois são discursos que circulam socialmente de um passado em que a elite blumenauense queria esconder a pobreza, conforme destaca Samagaia (2010).

No Bairro Progresso, a formação de moradias em locais irregulares ao longo dos anos sinaliza a formação de favelas e con-

\footnotetext{
${ }^{6}$ Apesar de não ser o foco de nossas discussões neste momento, temos clareza de que é preciso aprofundar as questões que envolvem a relação entre pobreza, enchentes e deslizamentos, deslocamento de pessoas, processos de exclusão/inclusão, negação de direitos e o acirramento da desigualdade social em Blumenau.
} 
firma as análises de Samagaia (2010). Exemplo desta realidade é o território no entorno da escola, onde há um morro constituído de ocupações irregulares e conhecido popularmente pelos moradores da região como "Morro da Banana". Em 2008, quando o município passou por uma de suas maiores catástrofes climáticas, praticamente todas as moradias deste local foram destruídas pelos deslizamentos de terra. Devido a esse fato trágico para a região de Blumenau e do Vale do Itajaí, a escola pública, localizada neste território, passou a servir pela primeira vez como alojamento para os desabrigados do "Morro da Banana".

Por conta das cheias e deslizamentos, muitas famílias perderam suas casas e acabaram sendo "jogadas" em outros locais do município, incluindo o Bairro Progresso que não possui locais de alagamentos, mas possui áreas de risco de deslizamento de terra. Por conta disso, a escola passou a receber mais estudantes, principalmente, matrículas no Ensino Médio. Aos poucos foram construídas novas moradias no bairro, o que permitiu o ingresso de pessoas de outras localidades do município nesta unidade escolar. O Bairro Progresso,

Por se localizar em área sem interferência de enchentes e ainda possuir espaço físico para edificações torna-se bastante procurada como área para uso residencial. A municipalidade tem recomendado evitar edificações em pontos que estejam dentro das áreas de risco. Constatou-se, [...], no período 1980/2010, um crescimento da população na ordem de 1,9\% ao ano, ou seja, existiam 8.115 habitantes em 1980, passando para 14.271 em 2010. Seguindo o aumento populacional, o número de domicílios cresceu em 2,8 ao a- no, ou seja, haviam 1.813 de domicílios em 1980, passando para 4.180 em 2010 (BLUMENAU, 2016, p. 9).

Com o aumento na quantidade de domicílios no bairro, muitos desses sujeitos se encontram ainda desassistidos de políticas públicas fundamentais como saúde, educação e transporte. Sem as condições necessárias para uma vida digna, pois não houve a estruturação das escolas e das creches para receber mais crianças e adolescentes, nem a adequação do sistema de transporte com o aumento da população e, sobretudo, com a concentração de milhares de pessoas em apartamentos pequenos ou em casas em áreas de risco, constitui-se neste bairro um novo aglomerado subnormal, ou seja, uma nova favela que se localiza distante dos olhos da elite blumenauense e dos turistas. Cabe esclarecer que a realidade atual da pobreza no Bairro Progresso ainda não entrou nas estatísticas oficiais, pois o último Censo do IBGE e as informações disponibilizadas no site do município são de 2010.

Com relação à escola em questão, apesar desta possuir uma maioria de estudantes cujos contextos familiares são de classe média, dentre os 1.100 regularmente matriculados em 2016, 46 estudantes eram famílias beneficiárias do Programa Bolsa Família, isto é, famílias em situação de pobreza ou extrema pobreza. A questão é: (re)conhecemos que a pobreza existe e se materializa nos corpos e no modo de vida das crianças e adolescentes que têm adentrado a escola nas últimas décadas? Que leituras os docentes têm feito do território escolar, tendo em vista aspectos históricos, geográficos e sociais de contextos como este?

Volta-se a atenção para leitura das reali- 
dades presentes dentro e no entorno da escola, pois os estudiosos da relação entre educação e pobreza afirmam que, infelizmente, "os alunos pobres no Brasil são a maioria: 17 milhões de beneficiários do Programa Bolsa família em um contingente de 34 milhões, e a escola não os enxerga!" (YANNOULAS; ASSIS; FERREIRA, 2012, p. 345). Apesar deste trabalho se tratar de um estudo de caso, compreendemos que ele pode servir de dispositivo de reflexão em outros contextos educacionais e de questionamento aos profissionais que atuam em outras políticas públicas, tais como na saúde e na assistência social.

Neste caso específico, apesar da imagem de um município marcado pela ordem, pelo trabalho e pelo progresso, há uma realidade por entre seus vales e morros que precisa ser visibilizada, pois a pobreza existe também em Blumenau e as crianças e adolescentes pobres estão nas escolas. Ao negligenciarmos esta realidade, por meio de oIhares que homogeneízam os estudantes e suas famílias, incorremos na negação dos direitos mais fundamentais a essa população, dentre eles, o direito a permanência com qualidade na escola e o direito de saber-se pobre por meio da educação (ARROYO, 2015c).

Ao dar continuidade às reflexões sobre o papel da escola frente às desigualdades sociais presentes no seu território, é possível questionar também: como se tem articulado currículo e pobreza na educação básica? Como a escola vem promovendo ao pobre o direito de reconhecer as condições históricas e sociais de produção da pobreza?

\section{EDUCAÇÃO E POBREZA}

Até a década de 1950, as desigualdades escolares eram muito mais nítidas e reforçadas a partir de um currículo voltado à educação para a classe dominante, pelo fato de existir claramente uma separação entre os escolarizados (elite) e os que estavam fora do contexto escolar, tais como: pobres, negros, camponeses, trabalhadores, entre outros. Contudo, esta população, que até então era excluída da escola, ao adentrar este contexto, não conseguiu provocar mudanças significativas no currículo escolar. Se, como mostram Assis e Yannoulas (2012), praticamente não há na formação de professores a presença da temática da pobreza, não é de se esperar que no currículo da educação básica esta questão seja pautada com alguma centralidade.

Há na pobreza uma dimensão imprescindível de ser reconhecida que é a desigualdade material-econômica, mas também é preciso avançar na compreensão da sua multidimensionalidade (REGO; PINZANI, 2015). É preciso ampliar nossos olhares, perceber as desigualdades de gênero e raça/etnia, as composições familiares, os locais de residência, o acesso à cultura e à educação, entre outros. Especialmente no campo da educação, os profissionais necessitam ressignificar as noções que possuem acerca das crianças, adolescentes e famílias pobres que frequentam a escola, pois são muitas vezes carregadas de preconceitos. Compreende-se, portanto, que a pobreza possui múltiplas dimensões e precisa ser analisada pelos profissionais da escola desde a complexidade que a constitui, a começar pela leitura do espaço territorial de moradia dos sujeitos.

Tais desconhecimentos colocam, por vezes, os estudantes oriundos de famílias que são beneficiárias do Programa Bolsa Família em um lugar desprivilegiado em relação às 
outras, acarretando novos processos de exclusão e desigualdades educacionais. A escola que poderia ser um espaço importante de formação pessoal e profissional para estes sujeitos, acaba por promover a segregação dos estudantes pobres. Por vezes, culpabiliza o estudante e/ou sua família pobre pelo fracasso escolar, pois via um pensamento moral e preconceituoso, associa a pobreza à dificuldade de aprendizagem, por exemplo. Neste processo, o direito à educação é negado juntamente com outros direitos humanos, pois como reflete Arroyo (2015b, p. 25):

quando os dados mostram que a história do direito à educação é sobremaneira lenta e segregadora das crianças, dos adolescentes e jovens-adultos pobres, negros, indígenas, quilombolas, camponeses somos obrigados a aprofundar sobre que formas de olhar, tratar, segregar têm persistido nas relações de classe, sociais, políticas, econômicas, de produção e trabalho; têm persistido na negação de seus direitos à terra, território, trabalho, renda, teto e educação.

Apesar de compreendermos a escola, instituição pública vinculada a políticas e leis educacionais (BRASIL, 1988; 1996; 2004; 2008; 2012; 2015), como importante para formação dos sujeitos, para preparação destes para a vida e para o mundo do trabaIho, é consenso de que sozinha ela não modificará a realidade social e econômica desigual em nosso país. A escola não é e nem pode ser identificada como a salvadora do mundo, porém é responsável pela capacidade dos seres humanos compreenderem o mundo no qual vivem (ÁVILA, 2015). É responsável também pela não reprodução dos processos de exclusão vividos pelos sujeitos pobres, uma vez que, sendo a pobreza socialmente produzida, a escola tem reforçado essa produção. Ou seja, precisamos olhar para a escola procurando romper com maniqueísmos que ora colocam a escola como transformadora, ora como reprodutora do status quo. O processo de escolarização compõe uma trama complexa envolvendo aspectos pedagógicos, econômicos, culturais e políticos que agenciam trajetórias educacionais múltiplas, que precisam ser analisadas considerando as intersecções de gênero, raça/etnia, classe social (YANNOULAS; ASSIS; FERREIRA, 2012), e também de deficiência.

Contudo, o que vemos hoje nas escolas é que os conteúdos e os enfoques apresentados podem auxiliar somente em parte os estudantes pobres a perceberem-se na condição de pobreza mediante a interlocução que o docente irá fazer. Com isso, destacamos o papel também dos docentes nesta discussão, pois, de modo geral,

Os currículos assumem apenas a responsabilidade de oferecer aos(às) alunos(as) os conhecimentos acumulados sobre a natureza, a sociedade, o espaço, a história, a linguagem etc., e têm ignorado e secundarizado o direito ao saber de si, ao saber-se no mundo, na sociedade, na natureza, nas relações sociais, econômicas e políticas, no padrão de trabalho, de produção, de apropriação-segregação do espaço da terra e da renda. Conhecer-se nesses padrões sociais e políticos que os condicionam como pobres ao longo da história é a síntese do seu direito ao conhecimento que a escola, a docência, os currículos têm o dever de garantir-lhes (ARROYO, 2015c, p. 19-20).

Saber-se pobre, no processo de escolari- 
zação, significa então que os sujeitos que vivenciam esta situação possuem o direito de compreender os processos e condições econômicas, sociais e culturais que produzem essas desigualdades e que fazem com que uns sejam pobres e outros não. É papel da escola e dos docentes, problematizar junto aos estudantes o porquê da existência das situações de pobreza, da fome, do desemprego, para que estes possam compreender a sociedade em que vivem, desnaturalizar a pobreza presente em seu território e, ao mesmo tempo, provocar posições de enfrentamento visando o exercício da cidadania.

Consideramos que as condições básicas para que a população mais pobre possa ter sua cidadania plenamente assegurada, ou seja, tenha voz e vez e possa opinar na sociedade em que está inserida, passa pela desconstrução da noção de que os pobres precisam ser assistidos. O que os sujeitos pobres precisam é ter seus direitos sociais, culturais, econômicos, políticos e civis garantidos, pois a pobreza é uma violação dos direitos humanos (MENDONÇA, 2015). E "a efetivação concreta desses direitos na vida social são os verdadeiros indicadores do grau de profundidade de uma democracia" (REGO; PINZANI, 2015, p. 9). Assim, pode-se afirmar que enquanto existirem pessoas em situação de pobreza e extrema pobreza tendo seus direitos fundamentais negados, existirá também o impedimento do exercício da cidadania e o não reconhecimento destes sujeitos enquanto cidadãos, o que consequentemente impossibilitará a afirmação de que vivemos efetivamente em uma sociedade "democrática".

Demarca-se, no âmbito destas reflexões, a necessidade dos profissionais da educação (re)conhecerem a existência da pobreza e de outras formas de desigualdade no território escolar. Faz-se necessário, portanto, que a instituição educativa reveja suas ações político-pedagógicas no sentido da não reprodução destas desigualdades e formas de exclusão, e assim consolide seu compromisso com uma educação pautada na promoção e na garantia dos direitos humanos, bem como na análise e apoio das lutas históricas destes grupos. É certo que a escola sozinha "não é condição suficiente para a mudança radical da sociedade, mas é condição necessária para o exercício da cidadania" (YANNOULAS; ASSIS; FERREIRA, 2012, p. 349).

Nesse sentido, com este estudo sobre o caso de Blumenau/SC e do Bairro Progresso, buscou-se problematizar o papel da escola na sua relação com o território e com a vida de seus estudantes pobres. Entendemos que esta relação passa pela possibilidade de uma aproximação e implicação ética com estes sujeitos, com a desconstrução de olhares moralistas e culpabilizadores, costumeiramente lançados sobre oss estudantes, famílias e comunidades pobres. Diz respeito à criação de uma relação pedagógica implicada com a ampliação das lutas históricas em torno dos direitos humanos, em especial, aquelas ligadas à violação da liberdade e da igualdade que marcam a vida das pessoas pobres.

\section{CONSIDERAÇÕES FINAIS}

Este estudo se consistiu como uma investigação inicial que se limitou a analisar algumas informações, sabendo que muitas outras poderão compor este caso a partir de outras relações e aprofundamentos. Consideramos importante, em outros estudos, ampliar as análises deste contexto a 
partir de áreas disciplinares diversas e dos olhares de outros sujeitos, tal como dos estudantes e famílias beneficiárias do Programa Bolsa Família, dos docentes e gestores da escola.

Se, por um lado, espera-se que os profissionais da educação passem a (re)conhecer a realidade do território escolar e rever suas ações político-pedagógicas visando a não reprodução das desigualdades sociais nas relações educativas, por outro, é preciso fazer com que todos os envolvidos naquele contexto sejam chamados a participar desse processo com o intuito de promover uma discussão em torno da problemática da pobreza e da desigualdade social presente no território da escola e na vida dos estudantes que a frequentam.

Consideramos como possíveis os gestos educativos que garantam o direito a apropriação de saberes históricos e críticos sobre a produção social e econômica da desigualdade social que faz com que milhões de pessoas estejam em situação de pobreza em nosso país. Saber-se pobre é condição para o aumento da potência de ação destes sujeitos. Por fim, espera-se que este estudo possa servir de dispositivo para olhares interdisciplinares e problematizações mais amplas atravessadas pelas questões que envolvem a pobreza e de como as instituições educativas e seus profissionais conhecem ou não seus contextos de trabalho, como se relacionam e como esta realidade adentra ou não as escolas.

\section{REFERÊNCIAS}

ARROYO, M. G. Pobreza, Desigualdades e Educação. Módulo Introdutório: Curso de Especialização Educação, Pobreza e Desigualdade Social. Brasília, DF: MEC, 2015a.
ARROYO, M. G. O direito à educação e a nova segregação social e racial - tempos insatisfatórios? Educação em Revista, Belo Horizonte, v. 31 , n. 03, p. 15-47, jul./set., 2015b.

ARROYO, M. G. Pobreza e Currículo: uma complexa articulação. Curso de Especialização em Educação Pobreza e Desigualdade Social. Módulo IV. Brasília-DF: MEC, 2015c. ASSIS, S. G.; YANNOULAS, S. C. A pobreza na formação docente: a situação de pobreza na formação das futuras professoras. Revista Educação Unisinos, v. 16, n. 3, p.251261, set./dez., 2012.

AVILA, Á. Videoaula Módulo II. Curso de Especialização Educação, Pobreza e Desigualdade Social, 2015. Disponível em: <http://avea.epds.nute.ufsc.br/course/view .php?id=1000>. Acesso em: 30 dez. 2015.

BLUMENAU. Prefeitura Municipal de Blumenau. Bairro Progresso. Disponível em: <http://www.blumenau.sc.gov.br/downloa ds/seplan/perfil_bairros/bairro_progresso.p df.> Acesso em: 07 mar. 2016.

BRASIL.Constituição da República Federativa do Brasil 1988. Diário Oficial [da] República Federativa do Brasil, Brasília - DF, ano CXXVI, n. 191-a, p. 1, 5 out. 1988. Seção 1. Disponível em: <http://www.planalto.gov. br/ccivil_03/constituicao/constituicaocompi lado.htm>. Acesso em: 23 jul. 2016.

BRASIL. Lei no 9.394 de 20 de dezembro de 1996. Diário Oficial da União, Brasília - DF, p. 2783323 dez. 1996. Seção 1. Disponível em: <http://portal.mec.gov.br/seesp/arqui vos/pdf/lei9394_Idbn1.pdf>. Acesso em: 23 jul. 2016.

BRASIL. Lei $\mathrm{n}^{\circ}$ 0.836, de 9 de janeiro de 2004. Cria o Programa Bolsa Família e dá outras providências. Diário Oficial da União, Brasília - DF, p. 1, 12 jan. 2004. Seção 1. Disponível em: <http:// www.planalto.gov. 
br/ccivil_03/_ato2004-2006/2004/lei/l10.8 36.htm>. Acesso em: 25 jul. 2016.

BRASIL. Política Nacional de Educação Especial na Perspectiva da Educação Inclusiva. Ministério da Educação, Brasília - DF / Rio de Janeiro - RJ - Equipe da Secretaria de Educação Especial. 7 jan. 2008. Disponível em: <http://portal.mec.gov.br/arquivos/ pdf/politicaeducespecial.pdf $>$. Acesso em: 23 jul. 2016.

BRASIL. Decreto no 7.824, de 11 de outubro de 2012. Regulamenta a Lei no 12.711 , de 29 de agosto de 2012, que dispõe sobre o ingresso nas universidades federais e nas instituições federais de ensino técnico de nível médio. Diário Oficial da União, Brasília - DF, p. 6, 15 out. 2012. Seção 1. Disponível em: <http://www.planalto.gov.br/ccivil_03/ _ato2011-2014/2012/Decreto/D7824.htm>. Acesso em: 25 jul. 2016.

BRASIL. Lei № 13.146, de 6 de julho de 2015. Institui a Lei Brasileira de Inclusão da Pessoa com Deficiência (Estatuto da Pessoa com Deficiência). Diário Oficial da União, Brasília - DF, p. 2, 7 jul. 2015. Seção 1. Disponível em: <http://www.planalto.gov.br/ ccivil_03/_Ato2015-2018/2015/Lei/L13146. htm>. Acesso em: 23 jul. 2016.

IBGE. Instituto Brasileiro de Geografia e Estatística. Censo Demográfico. 2010.

JORNAL DE SANTA CATARINA. Blumenau é a cidade catarinense com o maior número de moradias em áreas precárias, segundo IBGE. Jornal de Santa Catarina, 2012. Disponível em: <http://diariocatarinense.clicrbs. com.br/sc/geral/noticia/2012/05/blumenau -e-a-cidade-catarinense-com-o-maior-nume ro-de-moradias-em-areas-precarias-segund o-ibge-3763313.html>. Acesso em: $30 \mathrm{dez}$. 2015.

MENDONÇA, E. Pobreza, direitos humanos, justiça e educação. Módulo II. Curso de Es- pecialização Educação, Pobreza e Desigualdade Social. Brasília, DF: MEC, 2015.

MOSER, M.; IJUIM, J. K. A Invisibilidade Sobre as Áreas de Concentração de Pobreza de Blumenau. REBELA, v.5, n.1, jan./mar. 2015.

REGO, W. L.; PINZANI, A. Pobreza e Cidadania. Módulo I. Curso de Especialização Educação, Pobreza e Desigualdade Social. Brasília, DF: MEC, 2015.

SAMAGAIA, J. A prática da invisibilidade social sobre as áreas de concentração de pobreza na imprensa de Blumenau (SC). 2010. 263 f. Tese. (Doutorado em Geografia) - Programa de Pós-Graduação em Geografia, UFSC, Florianópolis, 2010.

SAWAIA, B. B. Introdução: Exclusão ou inclusão perversa? In: SAWAIA, B.B. (org.). As artimanhas da exclusão: análise psicossocial e ética da desigualdade social. Petrópolis: Vozes, 2008.

TELES, A.; STEIN, R.H. Programas de transferência de renda e condicionalidades educacionais: acesso ao direito ou moralização do acesso? In: YANNOULAS, S.C. (coord.). Política educacional e pobreza: múltiplas abordagens para uma relação multideterminada. Brasília: Liber Livro, 2013.

VENTURA, M. M. O Estudo de Caso como Modalidade de Pesquisa. SOCERJ, v. 20, n. 5, p.383-386, set./out., 2007.

YANNOULAS, S.C.; ASSIS, S. G.; FERREIRA, K. M. Educação e pobreza: limiares de um campo em (re)definição. Revista Brasileira de Educação, v. 17, n. 50, p. 329-496, maio./ago., 2012.

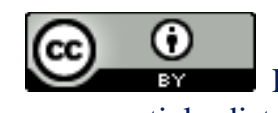

License information: This is an openaccess article distributed under the terms of the Creative Commons Attribution License, which permits unrestricted use, distribution, and reproduction in any medium, provided the original work is properly cited. 
Artigo recebido em 10 de março de 2017.

Avaliado em 19 de agosto de 2017.

Aceito em 11 de setembro de 2017.

Publicado em 22 de setembro de 2017.

\section{Como citar este artigo (ABNT):}

POTTMEIER, Sandra; GROFF, Apoliana Regi-

na; PROBST, Melissa. O "progresso" em

Blumenau/SC: educação, pobreza e desi-

gualdade social no território de uma escola.

Estação Científica (UNIFAP), Macapá, v. 7,

n. 2, p. 101-113, maio/ago. 2017. 